\title{
Frequency of Depression in Burn Patients at a Tertiary Care Hospital
}

\author{
Muhammad Asif, ${ }^{1}$ Owais Kareem, ${ }^{1}$ Bushra Ijaz, ${ }^{2}$ Naeem Ullah Leghari, ${ }^{1}$ Noman Amjad, ${ }^{1}$ Aliza Azhar ${ }^{1}$
}

\begin{abstract}
Background: Burns are physically, psychologically, and economically challenging injuries and the factors leading to them are many and understudied. Different studies have associated burn injuries with psychiatric disorders from different parts of the world.

Objective: To determine the frequency of depression among burn patients.

Methodology: This cross-sectional study was conducted at the Pak Italian Modern Burn Unit, Nishtar Medical University, Multan, and the Department of Psychiatry, Nishtar Medical University, Multan. Nonprobabilityconsecutivesampling technique wasused to collect the data fromstudysubjects, whichconsisted of 150 patients of burn. All patients were assessed by a single psychiatrist on the Hospital Anxiety and Depression scale (HADS) scalefor the screening of depression. Chi-square test was applied to determine the association between the socio-demographic factors of burn patients and depression.

Results: Of these 150 study cases, $91(60.7 \%)$ were male patients while $59(39.3 \%)$ were female patients. Mean age of our study cases was $33.94 \pm 8.88$ years. The frequency of depression was noted as $88(58.7 \%)$. Post-stratification Pearson chi-square test revealed significant associations between age $(p=0.001)$, residential status $(p=0.038)$, occupation $(p=0.000)$, etiology of burn $(p=0.044)$ and duration of illness $(p=0.000)$ with depression.

Conclusion: A high frequency of depression was noted among burn patients in our study. Depression was significantly associated with age, residential status, occupation, duration of illness, and etiology of the burn. Healthcare professionals treating such patients should anticipate depressive symptoms in these patients and treat them accordingly.
\end{abstract}

Keywords: Frequency, Depression, Burn, Multan, Pakistan

Article Citation: Asif M, Kareem O, Ijaz B, Leghari NU, Amjad N, Azhar A. Frequency of Depression in Burn Patients at a Tertiary Care Hospital. JSZMC 2020;11(3):03-07. DOI: https://doi.org/10.47883/jszmc.v11i03.59

\section{Introduction}

Burns is a prevalent and burdensome critical care problem. ${ }^{1}$ The priorities of specialized facilities focus on stabilizing the patient, preventing infection, and optimizing functional recovery. ${ }^{2}$ Research on burns has generated sustained interest over the past few decades, and several important advancements have resulted in more effective patient stabilization and decreased mortality, especially among young patients and those with burns of intermediate extent. ${ }^{1}$ Thermal burns from dry sources (fire or flame) and wet sources (scalds) account for approximately $80 \%$ of all reported burns and can be classified based on the depth of burn. ${ }^{2}$ Burn injuries are considered as a major health risk in its different forms and more than $95 \%$ of burns occur in developing and underdeveloped countries. Development of comprehensive burn centers and improvements in treatments of large burn injuries have dramatically increased the proportion of surviving patients. ${ }^{3}$
Burn injuries and their subsequent treatment cause one of the most excruciating forms of unimaginable pain. The psychological aspects of burn injury have been researched in different parts of the world, producing different outcomes. ${ }^{4}$ Studies have shown that greater levels of acute pain are associated with negative long-term psychological effects such as acute stress disorder, depression, suicidal ideation, and post-traumatic stress disorder for as long as 2 years after the initial burn injury. The concept of allostatic load is presented as a potential explanation for the relationship between acute pain and subsequent psychological outcomes.

Due to their long-term disabilities, burn injuries have become a great global health problem. Burns is regarded as an important public health problem in Pakistan. These injuries are of extensive morbidity leading to substantial medical costs. While it is reported as the sixth main cause of mortality, $28 \%$ of the survived patients cannot return to their previous functional level due to the severity of injuries and the consequences. ${ }^{6,7}$ In the last decades, the increase in

\footnotetext{
1. Department of Psychiatry \& Behaviourial Sciences, Multan Medical \& Dental College, Multan, UHS, Lahore, Pakistan.

2. Department of Community Medicine, Multan Medical \& Dental College, Multan, UHS, Lahore, Pakistan.

Correspondence: Dr. Owais Kareem, Senior Demonstrator, Department of Psychiatry \& Behaviourial Sciences, Multan Medical \& Dental College, Multan, Pakistan. 
survival rate following burn injury has prompted an increased focus on problems of rehabilitation, psychosocial adjustment, and psychosocial concomitants. The psychological aspects of burn injury have been researched in different parts of the world producing different outcomes. Psychological impairment has found to be present in $45.5 \%$ and $40 \%$ at baseline and follow up assessments respectively. ${ }^{8}$ Alvi et al ${ }^{9}$ from WahCantt reported $58 \%$ depression in burn patients while another study from conducted by Afraie et $\mathrm{al}^{3}$ reported $56 \%$ depression in burn patients.

There is only one study done in Pakistan to document depression in burn patients, which was done using a very small sample size of only 50 patients, so the results of this one study done with a small sample size could not be generalized on our large number of burns patients in Southern Punjab. The results will help clinicians to anticipate and treat depression at the early stages for better outcomes. Timely diagnosis and proper correction of the depressive symptoms will help to decrease disease morbidity and mortality. Management of depressive symptoms will also help to improve the quality of life of our patients. The objective of this study was to determine the frequency of depression among burnpatients.

\section{Methodology}

After approval from the ethical review committee, this cross-sectional study was conducted at the Pak Italian Modern Burn Unit of NishtarMedical University, Multan, and the Department of Psychiatry, NishtarMedical University, Multan from $17^{\text {th }}$ August 2017 to $23^{\text {rd }}$ August 2018. The sample size of 150 was calculated by the formula $\left(n=z^{2}\right.$ p q / d $d^{2}$ ) while taking 95\% confidence interval, $5 \%$ error of margin, $z$ value of 1.96 , and p-value of $58 .{ }^{9,10}$ Non-probability consecutive sampling technique was used to collect the sample. Data was collected using the interview method by a predesigned questionnaire. Male and female patients of 20 to 60 years of age with second and third-degree burns were included. Whereas patients with a history of drug addiction, history of depression prior to burning, history of suicidal attempts, pregnant ladies, patients with a history of chronic liver disease, diabetic mellitus, metabolic disorders, Hepatitis B or C, Myocardial infarction, Congestive heart failure,
Hypothyroidism, Hyperthyroidism, Stroke, and Tuberculosis, were excluded.

All included patients were assessed by a single psychiatrist on a validated Urdu version of the Hospital Anxiety and Depression Scale (HADS). ${ }^{11}$ Patients were categorized having depression on the HADS scoring equal/more than 8 . The outcome variable i.e. depression (Yes, No) was noted on the proforma specifically designed for the study along with socio-demographic details such as age, gender, degree of burn, literacy, occupation, residential status, monthly family income, and etiology of the burn.

Data were entered and analyzed with SPSS version 20. Quantitative data like age (in years), duration of illness, and Hospital Anxiety and Depression scale (HADS) score was presented as means \pm standard deviation. The qualitative data like gender, age groups, family income, occupation, literacy, etiology, residential status, and depression (yes, no) were presented as frequencies and percentages. Confounding variables like age, gender, family income, occupation, duration of illness, literacy, etiology, residential status were controlled by stratification.Post-stratification chi-square test was applied. P-value $\leq 0.05$ was considered as significant.

\section{Results}

Our study comprised a total of 150 patients meeting the inclusion criteria of our study. Among the total patients, the frequency of depression was noted as 88 (58.7\%). (Figure I) Of the total 150 study cases, 91 $(60.7 \%)$ were male patients while $59(39.3 \%)$ were female patients. (Table I) The mean age of our study cases was $33.94 \pm 8.88$ years (with minimum age of our study cases was 22 years while maximum age was 55 years). The mean age of the male patients was noted to be $33.41 \pm 7.88$ years while female patients was $34.76 \pm 10.24$ years. Our study results have indicated that the majority of our study cases i.e. $117(78.0 \%)$ were aged less than 40 years. (Table I) Of these 150 study cases, 54 (36\%) belonged to rural areas and $96(64 \%)$ belonged to urban areas. Of these 150 study cases, 59 (39.3\%) had monthly family income up to Rs. 25000 while $91(60.7 \%)$ had monthly family income more than 25000 rupees and 68 (45.3\%) were literate. (Table I) Among all 150 study cases, 28 (18.7\%) were laborers, 26 (17.3\%) were farmers, $5(3.3 \%)$ were office workers, 43 $(28.7 \%)$ were housewives, $11(7.3 \%)$ were students 
and $37(24.7 \%)$ were jobless. The mean duration of burn was $2.56 \pm 2.05$ months and 118 (78.7\%) had a duration of burn up to 3 months. Fire/flame burn was noted in $86(57.3 \%)$ and scald burn was noted in $64(42.7 \%)$ of our study cases. (Table I) Mean Hospital Anxiety and Depression scale (HADS) score was 9.53 \pm 2.26 and depression was noted in $88(58.7 \%)$ of our study cases and it was stratified with regards to gender, age, residential status, monthly family income, literacy, occupation, disease duration, and etiology. Poststratification Pearson chi-square test revealed significant associations between age $(p=0.001)$, residential status $(\mathrm{p}=0.038)$, occupation $(\mathrm{p}=$ $0.000)$, etiology of burn ( $\mathrm{p}=0.044)$ and duration of illness $(p=0.000)$ with depression.(Table II)

Figure I: Frequency of depression in burn patients. $(n=150)$

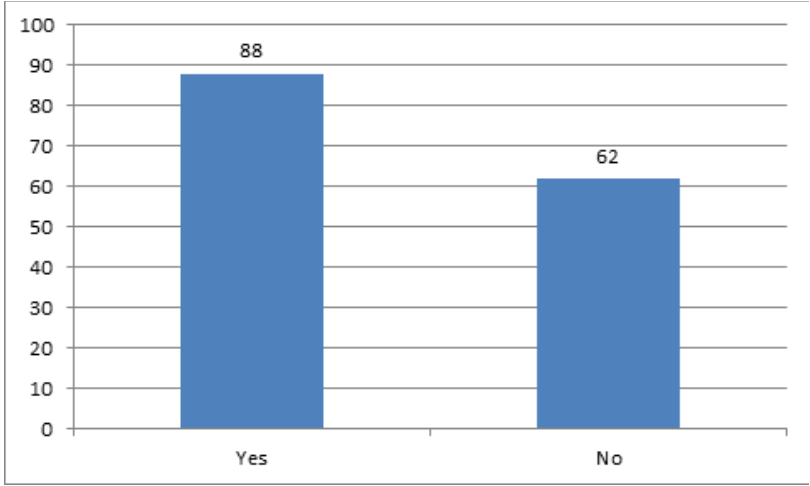

Table I: Distribution of sociodemographic factors among study cases. $(n=150)$

\begin{tabular}{|c|c|c|c|}
\hline \multicolumn{2}{|c|}{ Socio-demographic factors } & Frequency $(n)$ & Percentage $(\%)$ \\
\hline \multirow[t]{2}{*}{ Gender } & Male & 91 & 60.6 \\
\hline & Female & 59 & 39.3 \\
\hline \multirow[t]{2}{*}{ Age } & $20-40$ years & 117 & 78 \\
\hline & 41-60 years & 33 & 22 \\
\hline \multirow{2}{*}{$\begin{array}{l}\text { Residential } \\
\text { status }\end{array}$} & Rural & 54 & 36 \\
\hline & Urban & 96 & 64 \\
\hline \multirow[t]{2}{*}{ Family income } & Up to 25000 & 59 & 39.3 \\
\hline & More than 25000 & 91 & 60.7 \\
\hline \multirow[t]{2}{*}{ Literacy status } & Literate & 68 & 45.3 \\
\hline & Illiterate & 82 & 54.7 \\
\hline \multirow{6}{*}{$\begin{array}{l}\text { Occupational } \\
\text { status }\end{array}$} & Laborer & 28 & 18.7 \\
\hline & Farmer & 26 & 17.3 \\
\hline & Office worker & 5 & 3.3 \\
\hline & House wife & 43 & 28.7 \\
\hline & Student & 11 & 7.3 \\
\hline & Jobless & 37 & 24.7 \\
\hline \multirow{2}{*}{$\begin{array}{l}\text { Duration of } \\
\text { illness }\end{array}$} & Up to 3 months & 118 & 78.7 \\
\hline & $\begin{array}{l}\text { More than } 3 \\
\text { months }\end{array}$ & 32 & 21.3 \\
\hline \multirow{2}{*}{$\begin{array}{l}\text { Etiology of } \\
\text { burn }\end{array}$} & Flame & 86 & 57.3 \\
\hline & Scald & 64 & 42.7 \\
\hline
\end{tabular}

Table II: Stratification of depression with regard to socio-demographic factors. $(n=150)$

\begin{tabular}{|c|c|c|c|c|}
\hline \multirow{2}{*}{\multicolumn{2}{|c|}{ Sociodemographic factors }} & \multicolumn{2}{|c|}{ Depression } & \multirow{2}{*}{ P-value } \\
\hline & & \multirow{2}{*}{$\begin{array}{c}\text { Yes } \\
55(60.4 \%)\end{array}$} & \multirow{2}{*}{$\begin{array}{c}\text { No } \\
36(39.6 \%)\end{array}$} & \\
\hline \multirow{2}{*}{ Gender } & Male & & & \multirow{2}{*}{0.614} \\
\hline & Female & $33(55.9 \%)$ & $26(44 \%)$ & \\
\hline \multirow{2}{*}{ Age } & $21-40$ years & $60(51.1 \%)$ & $57(48.7 \%)$ & \multirow{2}{*}{0.001} \\
\hline & 41-60 years & $28(84.8 \%)$ & $5(15.1 \%)$ & \\
\hline \multirow{2}{*}{$\begin{array}{l}\text { Residential } \\
\text { Status }\end{array}$} & Rural & $38(70.3 \%)$ & $16(29.6 \%)$ & \multirow{2}{*}{0.038} \\
\hline & Urban & $50(52 \%)$ & $46(46.8 \%)$ & \\
\hline \multirow{2}{*}{ Family income } & $\begin{array}{l}\text { Up to Rs } \\
25,000\end{array}$ & $39(61.1 \%)$ & $20(33.8 \%)$ & \multirow{2}{*}{0.175} \\
\hline & $\begin{array}{l}\text { More than Rs } \\
25,000\end{array}$ & $49(53.8 \%)$ & $42(46.1 \%)$ & \\
\hline \multirow{2}{*}{ Literacy status } & literate & $44(44.4 \%)$ & $35.2(60 \%)$ & \multirow{2}{*}{0.186} \\
\hline & Illiterate & $44(53.6 \%)$ & $38(46.3 \%)$ & \\
\hline \multirow{6}{*}{$\begin{array}{l}\text { Occupational } \\
\text { status }\end{array}$} & Laborer & $7(25 \%)$ & $21(75 \%)$ & \multirow{6}{*}{0.000} \\
\hline & Farmer & $11(43.3 \%)$ & $15(57.6 \%)$ & \\
\hline & Office worker & $5(100 \%)$ & $0(0 \%)$ & \\
\hline & Housewife & $27(62.7 \%)$ & $16(37.2 \%)$ & \\
\hline & Student & $6(54.5 \%)$ & $5(45.4 \%)$ & \\
\hline & Jobless & $32(86.4 \%)$ & $5(13.5 \%)$ & \\
\hline \multirow{2}{*}{$\begin{array}{l}\text { Duration of } \\
\text { illness }\end{array}$} & $\begin{array}{l}\text { Up to } 3 \\
\text { months }\end{array}$ & $56(47.4 \%)$ & $62(52.5 \%)$ & \multirow{2}{*}{0.000} \\
\hline & $\begin{array}{l}\text { More than } \\
\text { 3months }\end{array}$ & $32(100 \%)$ & $0(0 \%)$ & \\
\hline \multirow{2}{*}{$\begin{array}{l}\text { Etiology of } \\
\text { burn }\end{array}$} & Flame & $44(51.1 \%)$ & $42(48.8 \%)$ & \multirow{2}{*}{0.044} \\
\hline & Scald & $44(68.7 \%)$ & $20(31.2 \%)$ & \\
\hline
\end{tabular}

\section{Discussion}

Burn injuries are caused by the application of heat, chemicals, electrical current, or radiation to the external or internal surface of the body, which causes destruction of the tissue. Burns are acute, unpredictable, and devastating forms of trauma that affect both the physical and psychological health of the victim. With improving medical care, many patients survive the acute phase of recovery and are left to deal with the long-term psychological effects of burns, which are complex and vary from patient to patient. The most common psychological problems faced by burn injury patients are pain, anxiety, depression, post-traumatic stress disorder, concern about bodily disfigurement, social isolation, and financial burden due to the prolonged duration of hospitalization and treatment required. ${ }^{10}$ Resolving the psychological problems that affect burn injury patients leads to a greater enhancement of their quality of life and wellbeing. Non resolution of these problems in the acute phase may cause them to progress to chronic psychiatric morbidities. ${ }^{11}$

Burn related pain during surgical procedures and physical rehabilitation is known to be associated with anxiety, and studies have shown that procedural-pain-associated anxiety increases as 
therapy progresses. Pain, anxiety, and distress are known to be associated with post-traumatic stress disorder in burn victims, whereas patients with higher rates of anxiety report more intense background pain on subjective assessment. Predisposing factors such as grief and mourning, pain, social isolation during hospitalization, and pre-burn depression have been associated with post-burn depression. Burn scars often lead to disfigurement, potentially causing an altered body image, lack of effective social functioning, and poor quality of life for the patient. Subjective body image dissatisfaction is an important predictor of post-burn psychological functioning twelve months after injury. A longer stay in the hospital has been associated with greater social isolation, a sense of loss of independence, economic dependency, loss of socio-occupational functioning, and increased distress in patients. Despite the overlapping interface between burn injuries and psychiatric morbidity, psychological help for burn patients is still under-addressed, and there is a need for a psychiatric team in the burns unit. $^{12}$

Our study comprised a total of 150 patients meeting the inclusion criteria of our study. Of these 150 study cases, $91(60.7 \%)$ were male patients while $59(39.3 \%)$ were female patients. Alvi et al ${ }^{9}$ from WahCantt reported $60 \%$ male gender predominance among burn patients, which is close to our study results. A study conducted by Ullrich et al ${ }^{13}$ from USA has also documented high male gender preponderance with $78 \%$ male patients which are close to our study results. Another study from Iran conducted by Afraie et al ${ }^{3}$ reported 1:1 male to female ratio, which is different from that of our study results. A study conducted by Jain et al $^{12}$ from India has also reported $54 \%$ male gender predominance which is in compliance with our study results. A study conducted by Thombs et $\mathrm{al}^{14}$ has also documented $54.5 \%$ male gender predominance, which is in compliance with our study results.

Mean age of our study cases was $33.94 \pm 8.88$ years (with minimum age of our study cases was 22 years while maximum age was 55 years). Mean age of the male patients was noted to be $33.41 \pm$ 7.88 years while that female patients was $34.76 \pm$ 10.24 years $(p=0.363)$. Our study results have indicated that the majority of our study cases i.e. $117(78 \%)$ were aged less than 40 years. Alvi et al ${ }^{9}$ from WahCantt reported $33.64 \pm 19$ years mean age of the burn patients which is close to our study results. Another study from Iran conducted by Afraie et $\mathrm{al}^{3}$ reported $34.12 \pm 8.11$ years mean age of the burn patients, which is close to our study results. A study conducted by Ullrich et al ${ }^{13}$ from USA has also documented $40.51 \pm 15.44$ years mean age of the burn patients, which is close to our study results. A study conducted by Jain et $\mathrm{al}^{12}$ from India has also reported $34.15 \pm 10.8$ years mean age, which is close to our study results. A study conducted by Thombs et al ${ }^{14}$ have also documented $33.1 \pm 17.8$ years mean age, which is in compliance with our study results.

Of these 150 study cases, 54 (36\%) belonged to rural areas and $96(64 \%)$ belonged to urban areas. Of these 150 study cases, 59 (39.3\%) had monthly family income up to Rs. 25000 while 91 (60.7\%) had monthly family income more than 25000 rupees and $68(45.3 \%)$ were literate. Alvi et al ${ }^{9}$ from WahCantt reported $76 \%$ burn patients belonging to urban areas, which are in line with our study results. Of these 150 study cases, 28 (18.7\%) were laborers, 26 (17.3\%) were farmers, $5(3.3 \%)$ were office workers, 43 $(28.7 \%)$ were housewives, $11(7.3 \%)$ were students and $37(24.7 \%)$ were jobless. Alvi et $\mathrm{al}^{9}$ from WahCantt reported $62 \%$ of the burn patients were either jobless, housewives, and students, which is close to our findings. A study conducted by Ullrich et al ${ }^{13}$ from USA has also documented $27.4 \%$ jobless burn patients, which is close to our study results.

The mean duration of burn was $2.56 \pm 2.05$ months and $118(78.7 \%)$ had a duration of burn up to 3 months. Fire/flame burn was noted in $86(57.3 \%)$ and scald burn was noted in $64(42.7 \%)$ of our study cases. Alvi et al ${ }^{9}$ from WahCantt also reported flam burns predominating cause of burn among the targeted population which is consistent to our findings. Another study from Iran conducted by Afraie et al ${ }^{3}$ reported $84 \%$ flame burn injuries, which is in compliance with our study results.

Depression was noted in $88(58.7 \%)$ of our study cases. Alvi et al ${ }^{9}$ from WahCantt reported $58 \%$ of the burn patients which is close to our study results. Another study from Iran conducted by Afraie et al ${ }^{3}$ reported $56 \%$ depression among burn patients which is close to our study results. A study conducted by Thombs et al ${ }^{14}$ has also documented $46 \%$ depression in burn patients, which is close to our study results. 


\section{Conclusion}

A high frequency of depression was noted among burn patients in our study. Depression was significantly associated with age, residential status, occupation, duration of burn, and etiology of the burn. Healthcare professionals treating such patients should anticipate depressive symptoms in these patients and treat them accordingly. This will improve the quality of life of these patients and their families.

\section{Author Contribution}

MA: Conception of work, drafting and revising. OK: Design of work and drafting. BI: Acquisition and Analysis of data and drafting. NL: Interpretation of data and revising. NA: Design of work and revising. AA: Acquisition and Analysis of data and revising.

All authors critically revised and approve its final version.

\section{Conflict of interest: None Resources of funding: Self}

\section{References}

1. Rowan MP, Cancio LC, Elster EA, Burmeister MD, Rose LF, Natesan F, et al. Burn wound healing and treatment: review and advancements. Crit Care 2015;19:243.doi: 10.1186/s13054-015-0961-2

2. Kagan RJ, Peck MD, Ahrenholz DH, Hickerson WL, Holmes J 4th, Korentager R, et al. Surgical management of the burn wound and use of skin substitutes: an expert panel white paper. J Burn Care Res 2013 Mar-Apr; 34(2):e60-79.

3. Arfaie A, Amiri S. Depressive Symptoms Among Survivors of Burn Injuries. J Clin Res Governance 2014;3(1): DOI: 10.13183/jcrg.v3i1.106.

4. Gamst-Jensen H, Vedel PN, Lindberg-Larsen VO, Egerod I. Acute pain management in burn patients: appraisal and thematic analysis of four clinical guidelines. Burns 2014 Dec;40(8):1463-9.

5. Chester SJ, Stockton K, De Young A, Kipping B, Tyack Z, Griffin B, et al. Effectiveness of medical hypnosis for pain reduction and faster wound healing in pediatric acute burn injury: study protocol for a randomized controlled trial. Trials 2016 Apr 29;17(1):223. doi: 10.1186/s13063-016-1346-9.
6. Mason ST, Esselman P, Fraser R,Schomer K, Truitt A, Johnson K. Return to work after burn injury: a systematic reviewJ Burn Care Res 2012;33:1101-9.

7. Jeschke MG, Pinto R, Kraft R, Nathens AB, Finnerty $\mathrm{CC}$, Gamelli RL, et al. Morbidity and survival probability in burn patients in modern burn care. Crit Care Med 2015 Apr;43(4):808-15.

8. Van Loey NE, Van Son MJ. Psychopathology and psychological problems in patients with burn scars: epidemiology and management. Am J ClinDermatol 2003;4(4):245-72.

9. Alvi T, Assad F, Aurangzeb, Malik MA. Anxiety and depression in burn patients. J Ayub Med CollAbbottabad 2009 Jan-Mar;21(1):137-41.

10. Asmr Y, Beza L, Engida H, Bekelcho T, Tsegaye N, Aschale Y. Assessment of knowledge and practices of standard precaution against blood borne pathogens among doctors and nurses at adult emergency room in Addis Ababa, Ethiopia. Emerg Med Int 2019 Apr 23;2019:2926415. doi: 10.1155/2019/2926415.

11. Mumford DB, Tareen IA, Bajwa MA, Bhatti MR, Karim $R$. The translation and evaluation of an urdu version of the hospital anxiety and depression scale. ActaPsychiatrScand 1991 Feb;83(2):81-5.

12. Jain M, Khadilkar N, De Sousa A. Burnrelatedfactorsaffectinganxiety, depression and selfesteem in burnpatients: an exploratorystudy. Ann Burns Fire Disasters 2017 Mar 31;30(1):30-34.

13. Ullrich PM, Askay SW, Patterson DR. Pain, depression, and physicalfunctioningfollowingburn injury. RehabilPsychol 2009 May;54(2):211-6.

14. Thombs BD, Haines JM, Bresnick MG, Magyar-Russell G, Fauerbach JA, Spence RJ. Depression in burn reconstruction patients: symptom prevalence and association with body image dissatisfaction and physical function. Gen Hosp Psychiatry. 2007 Jan-Feb;29(1):1420. 